\title{
Acriflavine immobilized onto polyethyleneimine-wrapped carbon nanotubes/gold nanoparticles as an eletrochemical sensing platform
}

\author{
AZADEH AZADBAKHT ${ }^{\mathrm{a}, *}$ and AMIRREZA ABBASI ${ }^{\mathrm{b}}$ \\ ${ }^{a}$ Department of Chemistry, Faculty of Science, Khorramabad Branch, Islamic Azad University, Khorramabad, \\ Iran \\ ${ }^{\mathrm{b}}$ Faculty of Chemistry, Razi University, 67194, Kermanshah, Islamic Republic of Iran \\ e-mail: Azadbakht.a@gmail.com
}

MS received 19 August 2015; revised 23 October 2015; accepted 4 December 2015

\begin{abstract}
Multi-walled carbon nanotubes wrapped by polyethyleneimine (PEI) and functionalized with a carboxylic acid group (CNT-COOH) were deposited with gold nanoparticles (AuNPs) which has been utilized as a platform to immobilize poly(acriflavine)(PAF) and used as modified electrode (AuNPs/PEI/CNT$\mathrm{COOH} / \mathrm{PAF})$. Electrocatalytic reduction of hydrogen peroxide $\left(\mathrm{H}_{2} \mathrm{O}_{2}\right)$ on the surface of the modified electrode was investigated by cyclic voltammetry and electrochemical impedance spectroscopy (EIS) methods. The cyclic voltammetric results indicated the ability of modified Au electrode to catalyze the reduction of $\mathrm{H}_{2} \mathrm{O}_{2}$. AuNPs/PEI/CNT-COOH nanocomposite combined the advantages of PEI, well dispersed CNT-COOH and in situ formed AuNPs, endowed with high stability to the enzyme-free sensor.
\end{abstract}

Keywords. Hydrogen peroxide; polyethyleneimine; gold nanoparticles; electrocatalytic reduction.

\section{Introduction}

Acriflavine, first synthesized in 1912, is a kind of antiseptic agent, orange or brown dye and a medicine against sleeping sickness. The monomer is widely used for photosensitizer, ${ }^{1}$ analytical regents for sensing, ${ }^{2}$ acid-base indicator ${ }^{3}$ and luminescence sensors ${ }^{4}$ among many others. Nevertheless, poly(acriflavine) (PAF) is rarely studied. In the literature, ${ }^{5,6}$ the PAF film was proposed to sense nicotinamide adenine dinucleotide (NADH), nitrite and sulfur oxoanions. Also, PAF film entrapped flavin adenine dinucleotide (FAD) was used to catalyze $\mathrm{NAD}^{+}$. There is a redox reaction (in which the redox peak potential is around $0.25 \mathrm{~V} v s . \mathrm{Ag} / \mathrm{AgCl}$ ) of poly(acriflavine) film in acidic solution and the PAF-modified film can lower the oxidation potential of $\mathrm{NADH}$ from 0.65 to $0.22 \mathrm{~V}$ (vs. $\mathrm{Ag} / \mathrm{AgCl}$ ). This class of polymer films, containing phenyl or amine groups in the structure such as polyaniline, has been proposed for use in biosensors ${ }^{7}$ and electrochemical devices, ${ }^{8}$ Generally, acriflavine exists in two forms: anacriflavine hydrochloride in acidic solution and in neutral solution as anacriflavine..$^{2,9,10}$

The detection of hydrogen peroxide $\left(\mathrm{H}_{2} \mathrm{O}_{2}\right)$ is very important in various fields including clinical, food, pharmaceutical and environmental analysis. Because $\mathrm{H}_{2} \mathrm{O}_{2}$ is a chemical threat to the environment and the

\footnotetext{
*For correspondence
}

production of enzymatic reactions, at the same time, it has been recognized as one of the major factors in the progression of important diseases. ${ }^{11}$ Accurate and reliable determination of $\mathrm{H}_{2} \mathrm{O}_{2}$ has been widely investigated using chromatography, ${ }^{12}$ spectrophotometry ${ }^{13}$ and electrochemistry. ${ }^{14-16}$ Among these methods, electrochemistry technique based on a simple and low cost electrode has been extensively applied for accurate determination of $\mathrm{H}_{2} \mathrm{O}_{2}$. Some inorganic materialmodified electrodes for the determination of $\mathrm{H}_{2} \mathrm{O}_{2}$ have attracted more attention owing to its stability and convenience of electron transfer. The materials include nanoparticles, perovskite-type oxide, inorganic-organic composite materials, inorganic-incorporated biology complex membranes, polyelectrolytes (PEs), and carbon nanotubes (CNTs). ${ }^{17-20}$ CNTs have high aspect ratio, nanometer dimensions and good electrical conductivity compared with conventional carbon materials used in electrochemistry such as glassy carbon (GC), graphite and carbon fiber. ${ }^{21}$

However, the dispersion of CNTs is not good enough to form an even film on the surface of the electrode. ${ }^{22}$ Based on the electron donor and acceptor interaction between PEs and CNTs, PEs are used to disperse CNTs to overcome this shortage. Another interesting nanomaterial is gold nanoparticles (AuNPs). Because the electrons can move freely, the electric field of the surface of AuNPs is largely enhanced which caused the wide application of AuNPs. Based on the respective 
advantages of CNTs and AuNPs, the composites containing both PEs-dispersed CNTs and AuNPs will bring some special properties and potential of applications. Guo et al. ${ }^{23}$ deposited AuNPs on the composite which was layer-by-layer assembly of CNTs and chitosan. The obtained nanomaterial was then grown on polystyrene templates to detect dopamine. Si et al. ${ }^{24}$ prepared a positively charged AuNPs which were further immobilized on the negatively charged CNTs/GC by electrostatic interaction. Importantly, when the AuNPs were formed in situ on the surface of CNTs instead of simply mixing of these materials, the stability of the composites would be improved greatly, which made the performance of sensor more stable.

In this work, we prepared a composite containing polyethyleneimine (PEI)-dispersed CNTs and AuNPs which were formed in situ on the surface of CNTsPEI. Using PEI catalyzed reduction of $\mathrm{HAuCl}_{4}{ }^{25}$ and thus greatly improved the binding stability of AuNPs onto the CNTs. The acriflavine was immobilized on the modified Au electrode through electrodeposition by consecutive potential cycling of the working electrode between $-0.05 \mathrm{~V}$ and $+0.8 \mathrm{~V}(v s$. $\mathrm{Ag} / \mathrm{AgCl})$ in an acetate buffer solution ( $\mathrm{pH} 4$ ) containing $1.5 \times 10^{-3} \mathrm{M}$ acriflavine and then the modified electrode was utilized as an electrochemical sensor for the highly sensitive determination of hydrogen peroxide.

\section{Experimental}

\subsection{General methods and materials}

Multiwalled carbon nanotubes with $95 \%$ purity (10$20 \mathrm{~nm}$ diameter) and $1 \mu \mathrm{m}$ length were obtained from Nanolab (Brighton, MA). Polyethylenimine (PEI, branched, Mw 10,000), hydrochloric acid (37\%), potassium ferricyanide $\left(\mathrm{K}_{3} \mathrm{Fe}(\mathrm{CN})_{6}\right)$, potassium ferrocyanide $\left(\mathrm{K}_{4} \mathrm{Fe}(\mathrm{CN})_{6} \cdot 4 \mathrm{H}_{2} \mathrm{O}\right)$, hydrogen tetrachloroaurate $\left(\mathrm{HAuCl}_{4} \cdot 4 \mathrm{H}_{2} \mathrm{O}\right)$ and potassium chloride $(\mathrm{KCl})$ were purchased from Merck (Germany) and Fluka. 3, 6-diamino-10-methylacridinium chloride (acriflavine) was produced by Sigma and used as received without further purification. All other chemicals were of analytical reagent grade and used without further purification. Solutions were deaerated by bubbling high purity $(99.99 \%)$ of nitrogen gas through them prior to the experiments. All experiments were carried out at ambient temperature of $25 \pm 1{ }^{\circ} \mathrm{C}$.

\subsection{Apparatus}

Electrochemical experiments were performed via using a rAutolab III (Eco Chemie B.V.) potentiostat/ galvanostat and NOVA 1.8 software. A conventional three electrode cell was used with an $\mathrm{Ag} / \mathrm{AgCl}$ electrode $(\mathrm{KCl} 3 \mathrm{M})$ as the reference electrode, a Pt wire as counter electrode and a modified Au as working electrode. The cell was a one compartment cell with an internal volume of $10 \mathrm{~mL}$. JENWAY $\mathrm{pH}$ meter (model 3345) was used for $\mathrm{pH}$ measurements. To obtain information about the morphology and size of the particles, scanning electron microscopy (SEM) was performed using an X-30 Philips instrument.

\subsection{Preparation of AuNPs/PEI/CNT-COOH composites}

CNTs were purified by refluxing in $3 \mathrm{M}$ nitric acid for $12 \mathrm{~h}$ at $150^{\circ} \mathrm{C}$. After subsiding, the sediments were washed with double deionized water. The suspension was suction filtered and subsequently dried at $60^{\circ} \mathrm{C}$. Then, washed and filtered until the filtrate was neutral, and the resultant solid was sonicated in the mixed solution of $\mathrm{HNO}_{3}$ and $\mathrm{H}_{2} \mathrm{SO}_{4}(1: 3, \mathrm{v} / \mathrm{v})$ for $3 \mathrm{~h}$. Then, the $\mathrm{pH}$ of the CNTs was adjusted to 8.0 using $\mathrm{NaOH}(15 \%)$ and centrifuged and dried subsequently. Then, the expected acid-oxidized carbon nanotube was obtained.

The preparation of the nanocomposite was according to the method in literature. ${ }^{25}$ Briefly, $3.4 \mathrm{mg}$ of $\mathrm{CNT}-\mathrm{COOH}$ was distributed in $10 \mathrm{~mL}$ double deionized water. Subsequently, $0.7 \mathrm{~mL}$ PEI aqueous solution $(1 \mathrm{M})$ and $2 \mathrm{~mL} \mathrm{HAuCl}_{4}(18 \mathrm{mM})$ were added to it and the mixture was heated in a $70^{\circ} \mathrm{C}$ water bath for $2 \mathrm{~h}$ to reduce $\mathrm{HAuCl}_{4}$ to AuNPs. Next, $1.5 \mathrm{~mL}$ double deionized water was added to the precipitation to obtain the sensing nanocomposite of AuNPs/PEI/CNT-COOHas demonstrated in figure 1.

Cationic PEI was coated onto CNT-COOH by electrostatic force. More critically, amines on PEI possessed high affinity for physisorption along the CNT-COOH surface which was similar to the polymer wrapping process. $^{26,27}$ The high density of imino-groups on PEI played an important role in the adsorption of anionic $\mathrm{AuCl}_{4}^{-}$followed by its reduction. For comparison, PEI was fabricated by preparing $5 \mu \mathrm{L}$ of $5 \%(\mathrm{v} / \mathrm{v})$ PEI in ethanol.To investigate the role of CNT-COOH in this nanocomposite, AuNPs/PEI was also prepared as described above without CNT-COOH.

\subsection{Electrode modification}

The working electrode was an Au disk electrode with a diameter of $3 \mathrm{~mm}$. Prior to each treatment, the $\mathrm{Au}$ working electrode (Metrohm) was polished with alumina slurry down to $0.05 \mathrm{~mm}$ on a polishing cloth 


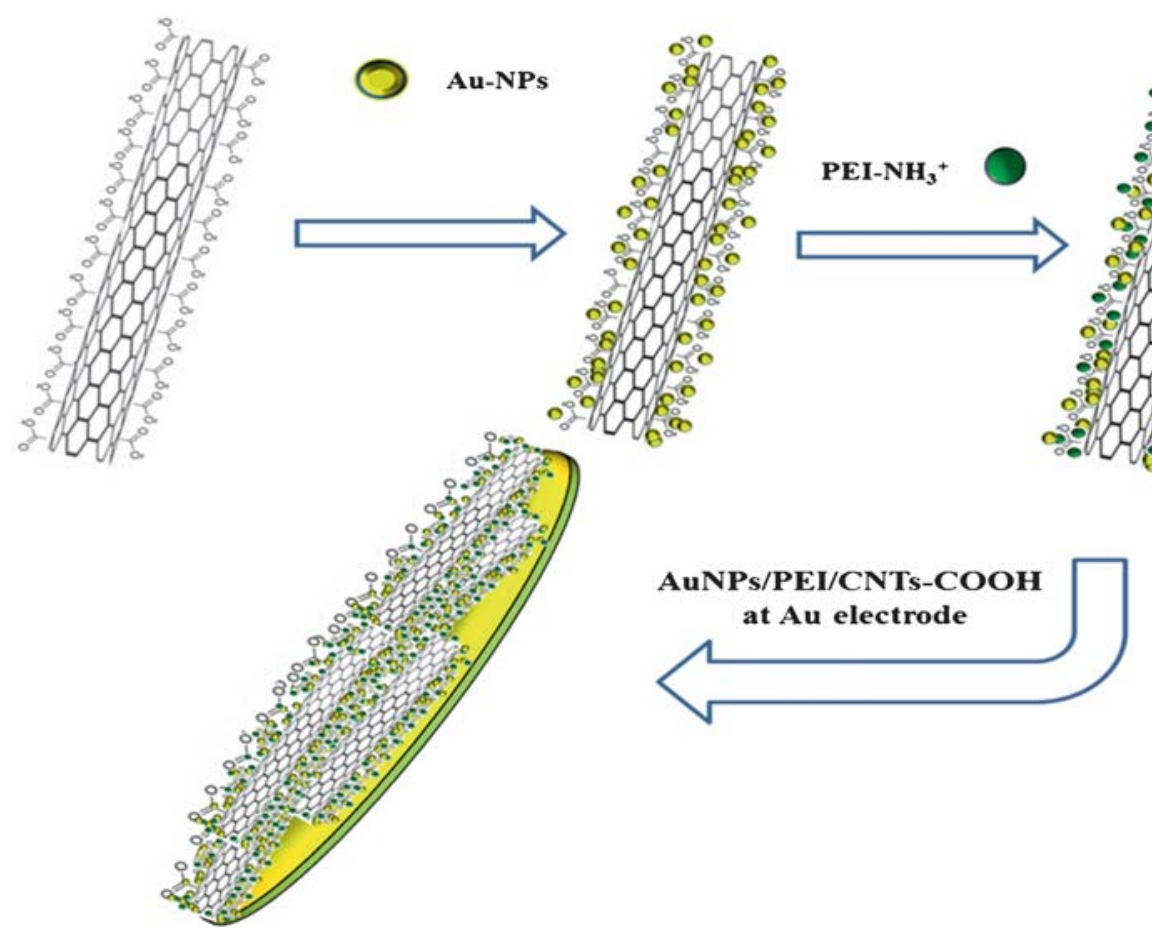

Figure 1. Overall preparative process of the $A u / A u N P s / P E I / C N T-C O O H$ electrode.

followed by sonication in distilled water and absolute ethanol. Then the Au electrode was electrochemically cleaned by cycling the electrode potential between -0.4 and $1.2 \mathrm{~V} v s$. $\mathrm{Ag} \mid \mathrm{AgCl}$ electrode in $0.5 \mathrm{M} \mathrm{H}_{2} \mathrm{SO}_{4}$ at a scan rate of $100 \mathrm{mVs}^{-1}$ until the cyclic voltammetry characteristics for a clean Au electrode were obtained. Then, $10 \mu \mathrm{L}$ of AuNPs/PEI/CNT-COOH solution was cast on the surface of Au electrode and dried in air to form a film at electrode surface. Afterward, the electrode was thoroughly rinsed with water and kept at room temperature for further use. The nanocomposite could adhere on the surface of gold electrode strongly due to the good ability to form film of the polyelectrolyte and strong adsorption of AuNPs. ${ }^{28}$ Furthermore, the use of polymers as anchors for CNT has been justified. ${ }^{29}$ The nanocomposite contains a large number of amine groups that bind to the $\mathrm{COOH}-\mathrm{CNT}$ by an amide linkage. ${ }^{30}$ Concerning the $\mathrm{COOH}-\mathrm{CNT}$ interaction to PEI, when the electrode was prepared without PEI film, there was not a stable $\mathrm{COOH}-\mathrm{CNT}$ binding to the electrode surface. In order to quantitatively determine the stability of the $\mathrm{COOH}-\mathrm{CNT}$ binding to the electrode surface, cyclic voltammograms were performed with three electrodes immersed in the electrochemical cell in the presence of a $5 \mathrm{mM} \mathrm{K}_{3} \mathrm{Fe}(\mathrm{CN})_{6}$ solution. The coefficient variation of the redox peaks were $94.9 \%$ and $0.9 \%$ in five cycles, for the electrode prepared without and with PEI film, respectively.

For acriflavine immobilization, the Au/AuNPs/PEI/ CNT-COOH modified electrode was immersed in 0.1
$\mathrm{M}$ acetate buffer solution containing acriflavine. Electrodeposition of acriflavine onto Au/AuNPs/PEI/CNT$\mathrm{COOH}$ electrode was carried out by the consecutive potential cycling of the working electrode between $0.05 \mathrm{~V}$ and $+0.8 \mathrm{~V}(v s . \mathrm{Ag} / \mathrm{AgCl})$ in accetate buffer $\left(\mathrm{pH}\right.$ 4) containing $1.5 \times 10^{-3} \mathrm{M}$ acriflavine monomers at a scan rate of $50 \mathrm{mVs}^{-1}$ for 50 cycles. The other electrodes used such as Au/PEI and Au/AuNPs/PEI were fabricated by casting $10 \mu \mathrm{L}$ of $5 \%(\mathrm{v} / \mathrm{v})$ PEI and AuNPs/PEI on the surface of bare Au electrode, respectively.

\section{Results and Discussion}

\subsection{Characterization of the modified electrode by SEM}

Figure 2 shows the SEM images of the CNT-COOH (A) AuNPs/PEI/CNT-COOH (B) and Au/AuNPs/PEI/CNT$\mathrm{COOH} / \mathrm{PAFelectrode}(\mathrm{C})$. It can be seen in figure $2 \mathrm{a}$ that the CNT-COOH are endless with a rather smooth surface. Figure $2 b$ shows a representative image for the AuNPs attached to PEI/CNT-COOH. It is interesting to see that the AuNPs preferentially adhere to the surfaces of CNT-COOH rather than to other regions without $\mathrm{CNT}-\mathrm{COOH}$. It was assumed that the presence of CNT-COOH catalyzes the reduction of $\mathrm{HAuCl}_{4}$ to $\mathrm{Au}^{0}$, which makes the reduction of $\mathrm{HAuCl}_{4}$ preferably occur on the surfaces of CNT-COOH. ${ }^{25}$ Therefore, the AuNPs are selectively present at the side walls 


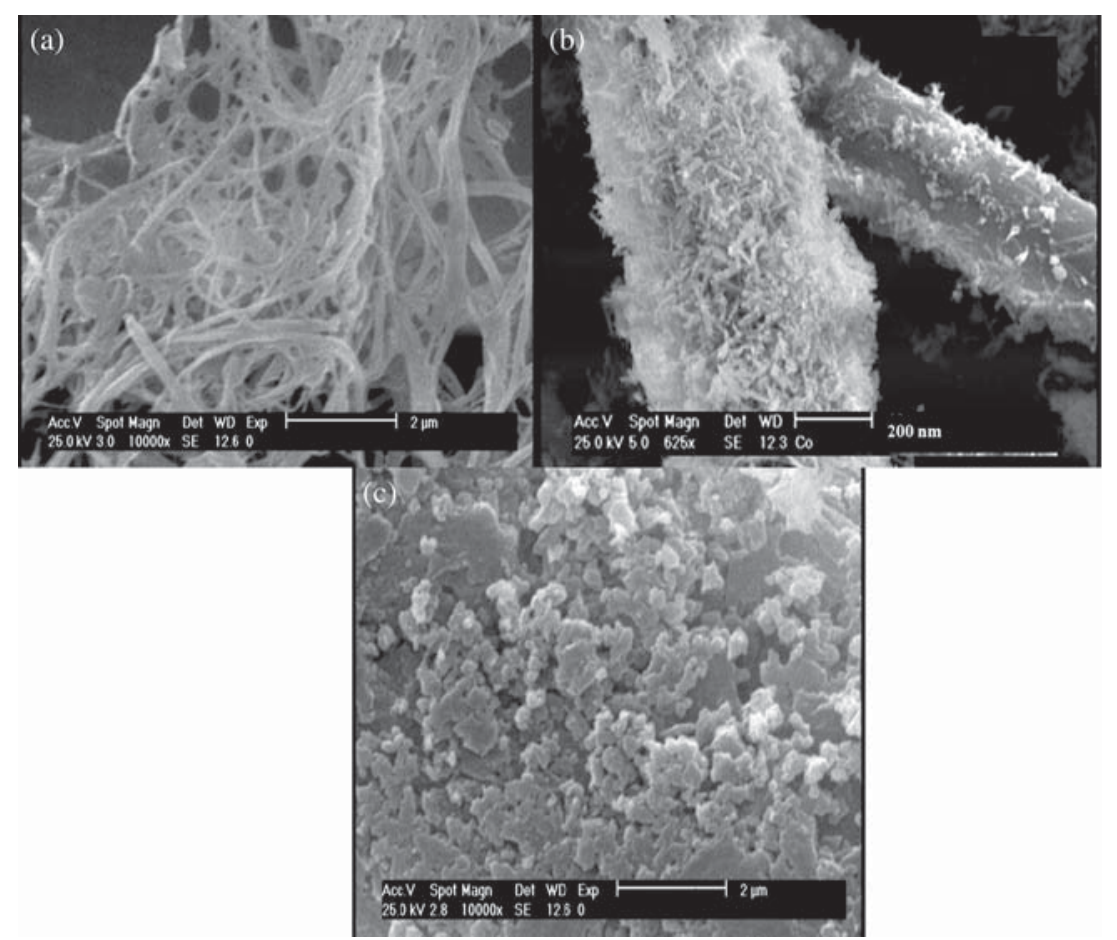

Figure 2. (a) Typical SEM image of CNT-COOH, (b) AuNPs/PEI/CNT$\mathrm{COOH}$ and (c) Au/AuNPs/PEI/CNT-COOH/PAF electrode.

of CNT-COOH and are not found in the areas without CNT-COOH. After PAF immobilization (figure 2c), the surface of the AuNPs/PEI/CNT-COOH nanocomposite became rougher and the morphology of the electrode surface is obviously changed, ${ }^{31}$ which implies that the PAF was successfully deposited on the surface of the AuNPs/PEI/CNT-COOH nanocomposite.

\subsection{Electrochemical Polymerization of acriflavine}

Figure 3 shows the consecutive cyclic voltammograms of poly(acriflavine) film deposition onto $\mathrm{Au} / \mathrm{AuNPs} / \mathrm{PEI} / \mathrm{CNT}-\mathrm{COOH}$ in $0.1 \mathrm{M}$ acetate buffer solution containing $1.5 \times 10^{-3} \mathrm{M}$ acriflavine monomer. During the first forward scan, acriflavine monomer started to oxidize at above $+0.3 \mathrm{~V}$ whereas on the reverse scan, one new cathodic peak appeared at around $-0.15 \mathrm{~V}$ and its counter part oxidation peak appeared at $+0.08 \mathrm{~V}$ in the subsequent cycle. Moreover, when the number of cycles increased, the peak current corresponding to the new reversible redox couple was increased. This result indicates that the oxidized product of acriflavine leads to the deposition of PAF onto the $\mathrm{Au} / \mathrm{AuNPs} / \mathrm{PEI} / \mathrm{CNT}-\mathrm{COOH}$ surface. In second type, electropolymerization of acriflavine onto electrode surface was also performed by holding the potential at $+0.8 \mathrm{~V}$ for $10 \mathrm{~min}$ in the buffer solution containing $1.5 \times 10^{-3} \mathrm{M}$ acriflavine. ${ }^{5}$ The cyclic voltammogram was characterized by one reversible redox couple, with the formal potential $\left(\mathrm{E}^{\circ \prime}=\left(\mathrm{E}_{\mathrm{pa}}+\mathrm{E}_{\mathrm{pc}}\right) / 2\right)$ occurring at $0.2 \mathrm{~V}$ (vs. $\mathrm{Ag} / \mathrm{AgCl}$ ). The reversible redox couple was attributed to the reduced and oxidized forms of PAF.

As the number of cycles increased, the redox peak current of PAF was found to be increased. This is an indication of PAF film growth onto $\mathrm{Au} / \mathrm{AuNPs} / \mathrm{PEI} / \mathrm{CNT}-\mathrm{COOH}$. To ascertain the effect of positive potential on the subsequent generation of reversible redox couple centered at $0.2 \mathrm{~V}$, voltammograms were carried out in which positive potential limit was progressively increased. The generation of new wave increased as the positive potential limit increased and reached maximum value at about $1 \mathrm{~V}$. Sweeping the potentials to more positive values did not result in the generation of additional material. These results confirmed that the oxidation of acriflavine results PAF film deposition onto $\mathrm{Au} / \mathrm{AuNPs} / \mathrm{PEI} / \mathrm{CNT}-\mathrm{COOH} .^{5}$

Cyclic voltammograms of PAF onto bare $\mathrm{Au}$ (a), $\mathrm{Au} / \mathrm{PEI}$ (b),Au/AuNPs/PEI (c) and Au/AuNPs/PEI/ $\mathrm{CNT}-\mathrm{COOH}$ (d) in $0.1 \mathrm{M}$ acetate buffer solution $(\mathrm{pH} 4)$ at a scan rate of $50 \mathrm{mVs}^{-1}$ were carried out. As can be seen in figure 4, a pair of weak redox peaks were observed when $\mathrm{Au} / \mathrm{PAF}$ and $\mathrm{Au} / \mathrm{PEI} / \mathrm{PAF}$ electrodes were used (curves $\mathrm{a}$ and $\mathrm{b}$ ) compared to the other modified electrodes (curves $\mathrm{c}$ and $\mathrm{d}$ ). As was previously reported, the anodic and cathodic process correspond to the $\mathrm{PAF}_{\mathrm{Ox}} / \mathrm{PAF}_{\mathrm{R}}$ redox couple. ${ }^{5} \mathrm{In}$ 


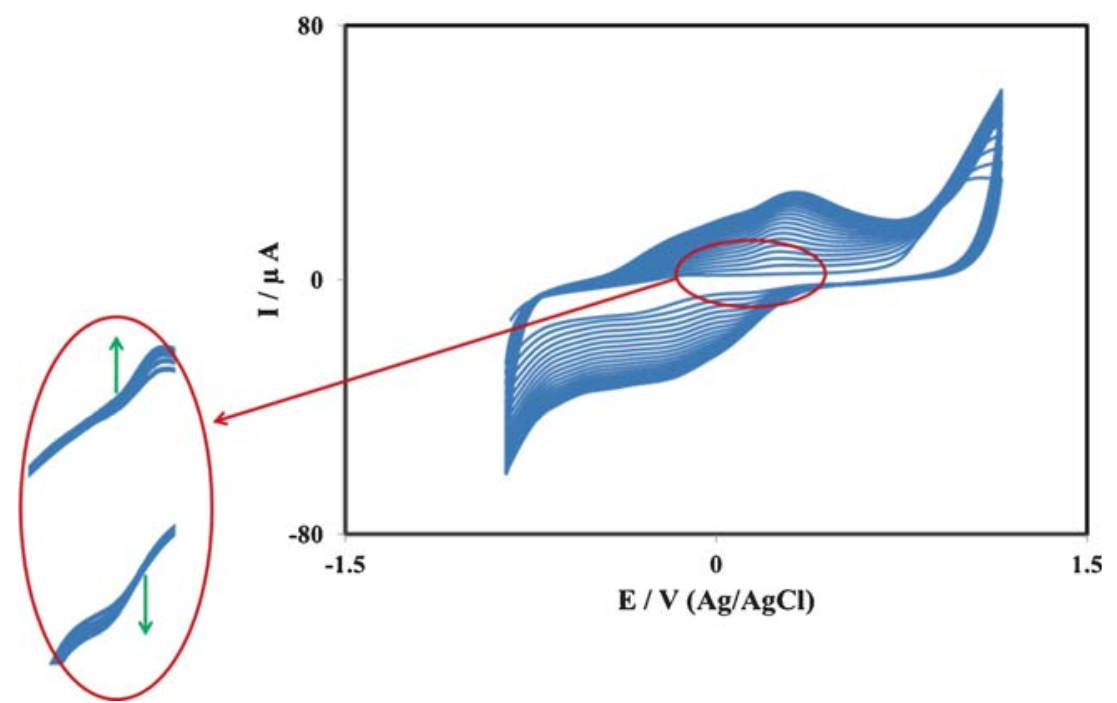

Figure 3. Consecutive cyclic voltammograms of Au/AuNPs/PEI/CNT$\mathrm{COOH}$ electrode in $0.1 \mathrm{M}$ acetate buffer solution containing $1.5 \times 10^{-3} \mathrm{M}$ acriflavine at a scan rate of $50 \mathrm{mV} \mathrm{s}^{-1}$.

order to improve the performance of the Au/PEI modified electrode, improvement of the mentioned electrode with other compounds with different properties (AuNPs and AuNPs/CNTs-COOH) were carried out (Au/AuNPs/PEI and Au/AuNPs/PEI/CNTs-COOH electrodes) and their $\mathrm{CV}$ recorded and compared with those obtained with other tested electrodes. As seen in figure 4, the Au/AuNPs/PEI/CNT-COOH/PAF (curve d) electrode improves the reversibility of the electrodic process (peaks potential separation was decreased to $85 \mathrm{mV}$ ). Also, the corrected peak current (after background correction) of the Au/AuNPs/PEI/CNT$\mathrm{COOH} / \mathrm{PAF}$ was calculated to be $309 \mu \mathrm{A}$ which is 1.47 times larger than that of Au/AuNPs/PEI/PAF $(210 \mu \mathrm{A})$.

Electrochemical impedance spectroscopy (EIS) technique is proven to be an effective method for probing the features of surface modified electrodes. EIS technique is capable of detecting small changes occurring at the solution-electrode interface. The interaction between a charged redox couple and the electrode surface is reflected by the charge-transfer resistance $\left(\mathrm{R}_{\mathrm{ct}}\right)$. The choice of the redox probe depends on various parameters such as the charge, hydrophobicity/hydrophilicity, size of the redox couple, and the chemical and physical properties of the modified electrodes. The interesting thing is to watch the changes that occur when the electrode surface is modified and it is best to select the redox probe that yields higher redox changes. Among the different redox probes, ferricyanide/ferrocyanide indicates the fastest Nernstian one-electron transfer reaction, for a kinetically facile system. So, normally this redox couple is chosen in the construction of the Nyquist plot.

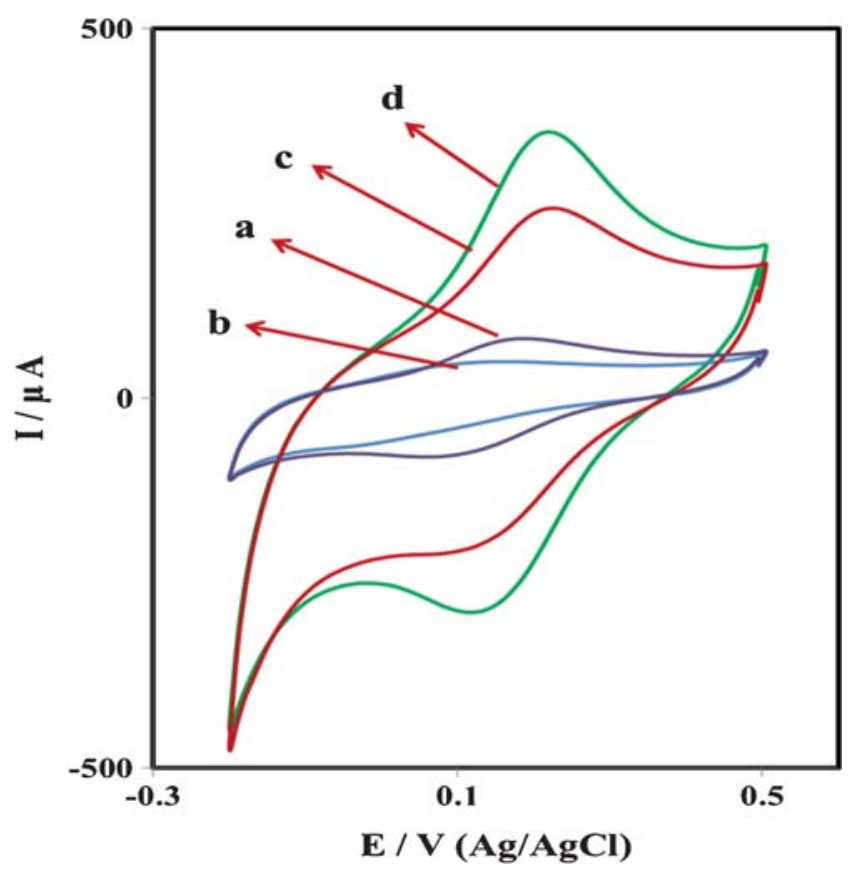

Figure 4. Cyclic voltammograms of Au/PAF (a), Au/PEI/ PAF (b), Au/AuNPs/PEI/PAF (c) and Au/AuNPs/PEI/CNT$\mathrm{COOH} / \mathrm{PAF}(\mathrm{d})$ in $0.1 \mathrm{M}$ acetate buffer solution $(\mathrm{pH} 4)$ at a scan rate of $50 \mathrm{mVs}^{-1}$.

Figure 5 shows the typical Nyquist plots for bare $\mathrm{Au}, \mathrm{Au} / \mathrm{PEI}, \mathrm{Au} / \mathrm{AuNPs} / \mathrm{PEI}, \mathrm{Au} / \mathrm{AuNPs} / \mathrm{PEI} / \mathrm{CNT}-$ $\mathrm{COOH}$ and $\mathrm{Au} / \mathrm{AuNP} / \mathrm{PEI} / \mathrm{CNT}-\mathrm{COOH} / \mathrm{PAF}$ electrodes recorded in $0.1 \mathrm{M} \mathrm{KCl}$ solution containing $0.5 \mathrm{mM} \mathrm{Fe}(\mathrm{CN})_{6}^{3-/ 4-}$ as the electrochemical redox marker. The impedance spectra were fitted to a modified Randle's equivalent circuit, as shown in the inset of figure 5, where $R_{s}$ represents the electrolyte resistance, 


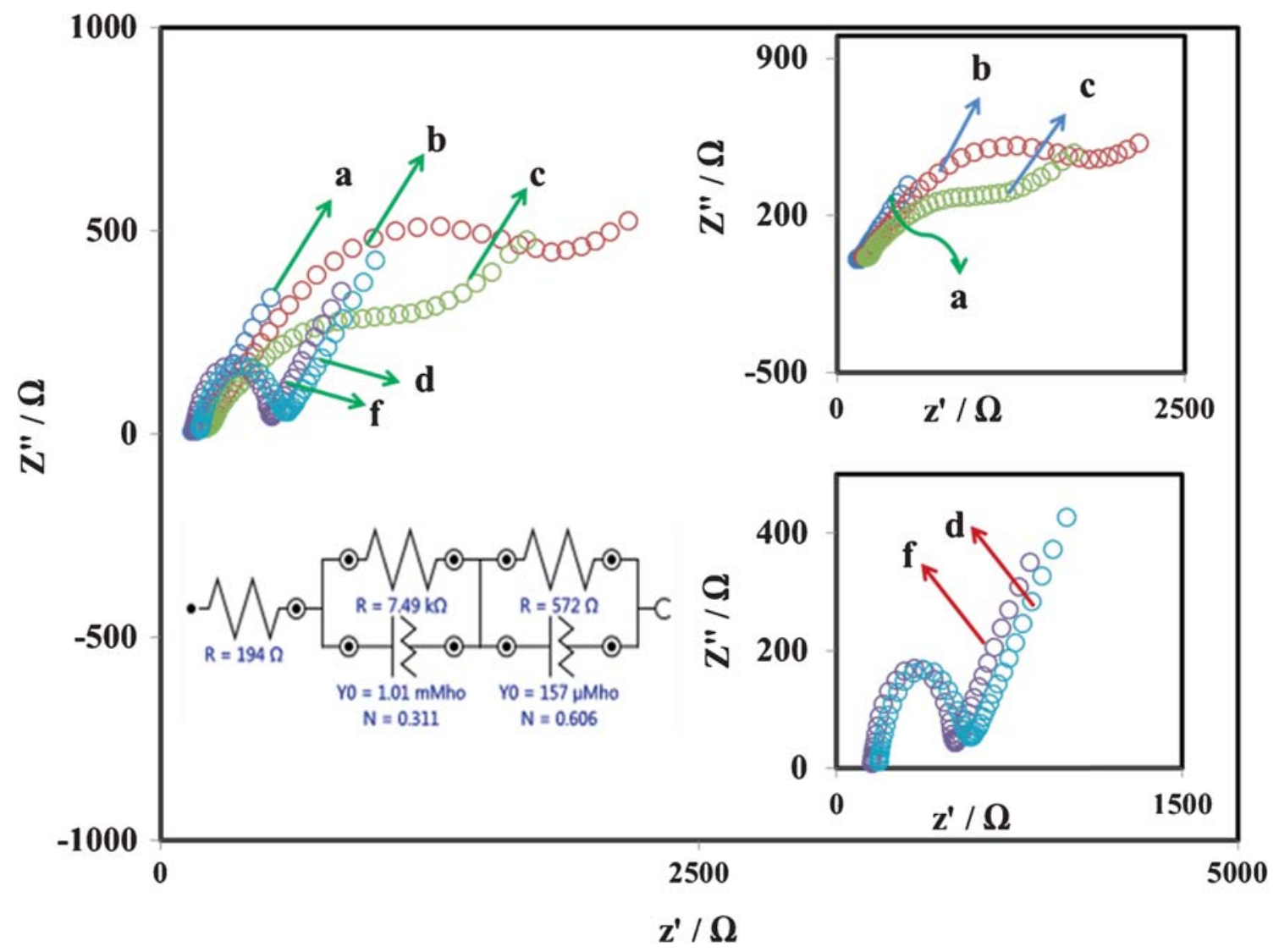

Figure 5. Nyquist plots for bare Au (curve a), Au/PEI (curve b), Au/AuNPs/PEI (curve c), $\mathrm{Au} / \mathrm{AuNPs} / \mathrm{PEI} / \mathrm{CNT}-\mathrm{COOH}$ (curve d) and Au/AuNPs/PEI/CNT-COOH/PAF (curve f) electrodes recorded in $0.1 \mathrm{M} \mathrm{KCl}$ solution containing $0.5 \mathrm{mM} \mathrm{Fe}(\mathrm{CN})_{6}^{3-/ 4-}$ in the frequency range of $10 \mathrm{kHz}-0.1 \mathrm{~Hz}$.

$\mathrm{C}_{\mathrm{dl}}$ is the double-layer capacitance, $\mathrm{R}_{\mathrm{ct}}$ is the chargetransfer resistance and $Z_{\mathrm{w}}$ is the Warburg impedance. The straight line at low frequency is related to the diffusion process known as Warburg element, while the high frequency semicircle is related to the electron transfer resistance $\left(\mathrm{R}_{\mathrm{ct}}\right)$, which controls the electron transfer kinetics of the redox probe at the electrode interface. The EIS at a bare Au electrode displays a very small semicircle and charge transfer resistance, which is a characteristic feature of the diffusion controlled electrochemical processes (figure 5a). After immobilization of PEI, the value of $R_{c t}$ is significantly increased to about $7.49 \mathrm{k} \Omega$ (figure $5 \mathrm{~b}$ ). It indicates hindrance to the electron transfer, confirming the successful immobilization of PEI onto the Au electrode surface.

After modification of PEI with AuNPs the electron transfer resistance $\left(\mathrm{R}_{\mathrm{ct}}\right)$ decreased, which proved that the assembly of AuNPs makes the electron transfer easier (figure 5c). Finally, when AuNPs/PEI/CNT$\mathrm{COOH}$ was cast at the surface of Au electrode the value of $R_{c t}$ is significantly decreased compared with $\mathrm{Au} / \mathrm{PEI}$ and $\mathrm{Au} / \mathrm{AuNPs} / \mathrm{PEI}$ electrodes (figure 5d). These results may be attributed to the positive charge of the AuNPs/PEI/CNT-COOH nanocomposite and the negative charge of the $\left[\mathrm{Fe}(\mathrm{CN})_{6}\right]^{3-/ 4-}$ that causes the electrostatic attraction between $\left[\mathrm{Fe}(\mathrm{CN})_{6}\right]^{3-/ 4-}$ and AuNPs/PEI/CNT-COOH nanocomposite with the result of lowering electron transfer kinetics on the electrode surface. Therefore, immobilization of AuNPs/PEI/CNT-COOH at the surface of $\mathrm{Au}$ electrode facilitates the electron transfer of the redox probe on the modified electrode. After modification of $\mathrm{Au} / \mathrm{AuNPs} / \mathrm{PEI} / \mathrm{CNT}-\mathrm{COOH}$ with PAF, the value of $\mathrm{R}_{\mathrm{ct}}$ is significantly decreased to about $760 \Omega$ (figure $5 \mathrm{f}$ ), confirming the successful immobilization of PAF onto $\mathrm{Au} / \mathrm{AuNPs} / \mathrm{PEI} / \mathrm{CNT}-\mathrm{COOH}$ electrode surface. These results indicate that the Au/AuNPs/PEI/CNT$\mathrm{COOH} / \mathrm{PAF}$ electrode could provide good electron conduction pathways between the electrode and electrolyte.

\subsection{Properties of the nano-structured Au/AuNPs/PEI/ CNT-COOH/PAF electrode}

The recorded cyclic voltammograms of $\mathrm{Au} / \mathrm{AuN}$ $\mathrm{Ps} / \mathrm{PEI} / \mathrm{CNT}-\mathrm{COOH} / \mathrm{PAF}$ film in $0.1 \mathrm{M}$ acetate buffer 
solution $(\mathrm{pH} \mathrm{4)}$ at different scan rates were recorded. Anodic and cathodic peak currents vs. the scan rate were plotted and the data revealed that both the anodic and cathodic peak currents are linearly proportional to the scan rate in the range of $10-75 \mathrm{mVs}^{-1}$, indicating a surface confined electrode process. The peak-to-peak potential separation is about $86 \mathrm{mV}$ at scan rates below $75 \mathrm{mV} \mathrm{s}^{-1}$, suggesting facile charge transfer kinetics over this range of sweep rates. At higher sweep rates peak separations begin to increase, indicating the limitation due to charge transfer kinetics. ${ }^{32}$ The shifts of peak potentials were proportional to the logarithm of the scan rate for scan rates higher than $100 \mathrm{mVs}^{-1}$.

The cyclic voltammograms of the Au/AuNPs/ $\mathrm{PEI} / \mathrm{CNT}-\mathrm{COOH} / \mathrm{PAF}$ was also found to be stable in the $\mathrm{pH}$ range between 1 to 7 . However, in basic solution the cyclic voltammogram of the Au/AuNPs/PEI/CNT$\mathrm{COOH} / \mathrm{PAF}$ was diminished. This behavior may arise due to the instability of the polymer film in basic solution. Since the modified electrodes had limited stability in buffers at $\mathrm{pH}>7$, we investigated the stability and electrochemical properties of prepared modified electrode in buffer solutions in the $\mathrm{pH}$ range 1-8 by recording the cyclic voltammograms. The results exhibited $\mathrm{pH}$ dependent voltammetric peak potentials, i.e., the anodic and cathodic peak potentials of the modified electrode were shifted to a less positive value with increasing $\mathrm{pH}$ of the electrolyte solution. In addition, the peak current values and peak area also decreased. The formal potential $\left(\mathrm{E}^{\circ}\right)$ of the PAF film was evaluated as the mean of the anodic and cathodic peak potentials of the cyclic voltammograms recorded at various $\mathrm{pH}$ values. The $\mathrm{E}^{\circ}$ vs. pH plot yields a straight line with a slope of 64 $\mathrm{mV}$ per unit $\mathrm{pH}$. It suggests that the overall redox reaction of the polymer film comprises a two-electron and two-proton process. ${ }^{33}$

\subsection{Electrocatalytic reduction of $\mathrm{H}_{2} \mathrm{O}_{2}$ at Au/AuNPs/ PEI/CNT-COOH/PAF electrode}

Application of the modified electrode for reduction of $\mathrm{H}_{2} \mathrm{O}_{2}$ was evaluated by cyclic voltammetry. Reduction of $\mathrm{H}_{2} \mathrm{O}_{2}$ at $\mathrm{Au} / \mathrm{AuNPs} / \mathrm{PEI} / \mathrm{CNT}-\mathrm{COOH}$ and $\mathrm{Au} / \mathrm{AuNPs} / \mathrm{PEI} / \mathrm{CNT}-\mathrm{COOH} / \mathrm{PAF}$ electrodes was investigated in the phosphate buffer solution (PBS) (pH 2). Figure 6 shows recorded cyclic voltammograms in the absence and presence of $2 \mathrm{mM}$ of $\mathrm{H}_{2} \mathrm{O}_{2}$ at scan rate of $50 \mathrm{mV} \mathrm{s}^{-1}$. As can be seen in figure $6, \mathrm{H}_{2} \mathrm{O}_{2}$ did not undergo reduction at Au/AuNPs/PEI/CNT-COOH electrode in the potential window of -0.5 to $0.8 \mathrm{~V}$ in PBS ( $\mathrm{pH}$ 2). However, presence of PAF film on $\mathrm{Au} / \mathrm{AuNPs} / \mathrm{PEI} / \mathrm{CNT}-\mathrm{COOH}$ electrode had a catalytic

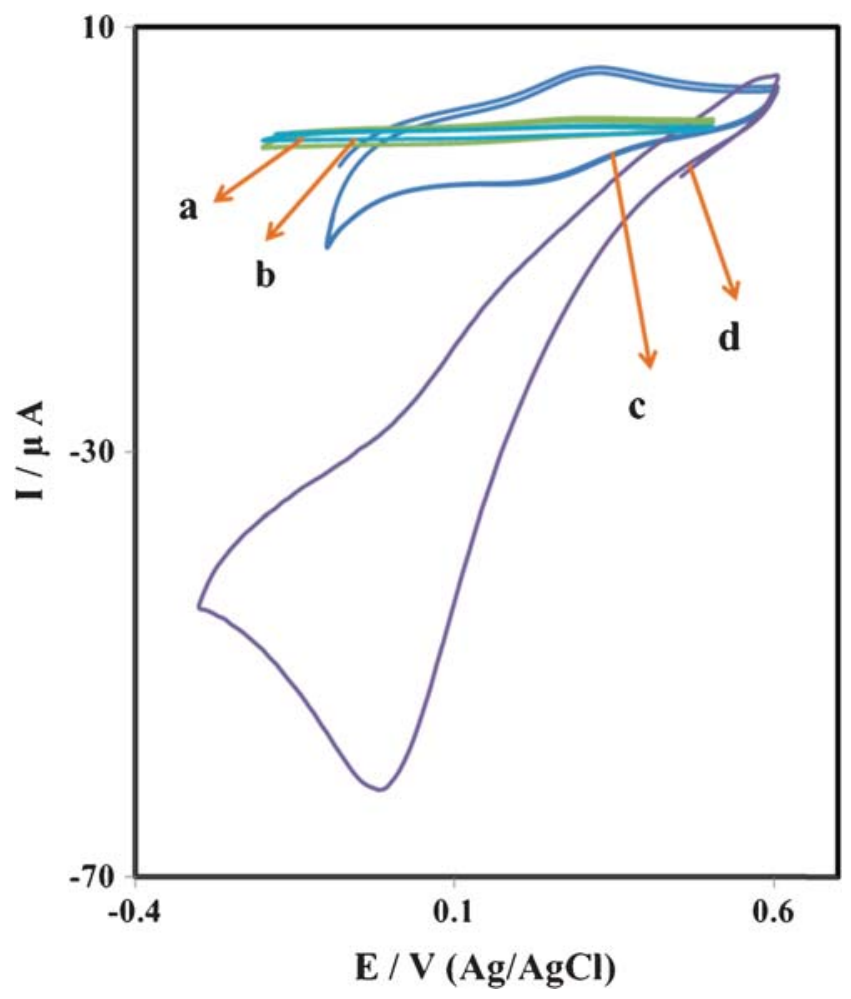

Figure 6. $\mathrm{CVs}$ of $\mathrm{Au} / \mathrm{AuNP} / \mathrm{PEI} / \mathrm{CNT}-\mathrm{COOH}$ (a and $\mathrm{b}$ ) and $\mathrm{Au} / \mathrm{AuNP} / \mathrm{PEI} / \mathrm{CNT}-\mathrm{COOH} / \mathrm{PAF}$ (c and $\mathrm{d}$ ) in the absence (a and c) and the presence (b and d) of $2 \mathrm{mM}$ of $\mathrm{H}_{2} \mathrm{O}_{2}$, respectively, at a scan rate of $50 \mathrm{mVs}^{-1}$.

effect for reduction of $\mathrm{H}_{2} \mathrm{O}_{2}$ (figure 6, curve d). This result reveals that PAF has excellent catalytic activity toward $\mathrm{H}_{2} \mathrm{O}_{2}$ determination.

To gain further insight into the electrochemical reactions at the different modified electrodes, the EIS experiments were performed in the presence of $4 \mathrm{mM}$ of $\mathrm{H}_{2} \mathrm{O}_{2}$ in $0.1 \mathrm{M}$ PBS ( $\mathrm{pH}$ 2). As can be seen in figure 7 for $\mathrm{Au}$ electrode, a semicircle curve was observed over the whole frequency region and the value of $R_{c t}$ is $948 \Omega$, indicating that the reaction is kinetically controlled (curve a). After immobilization of PAF at the surface of gold electrode, the value of $R_{c t}$ was significantly decreased to about $210 \Omega$ (curve b). The results indicate that the immobilized PAF decreased the charge transfer kinetics to about one-fourth of that at the bare $\mathrm{Au}$ electrode and it also confirmed that the presence of PAF film on Au electrode had a catalytic effect for reduction of $\mathrm{H}_{2} \mathrm{O}_{2}$. For Au/AuNPs/PEI/CNT$\mathrm{COOH} / \mathrm{PAF}$, the calculated charge transfer resistance is decreased (curve c), which proves that the assembly of AuNPs/PEI/CNT-COOH nanoparticles makes the electron transfer easier.

The deposition of AuNPs/PEI/CNT-COOH on the surface of modified electrode facilitated the electron transfer of the electrochemical probe on the 


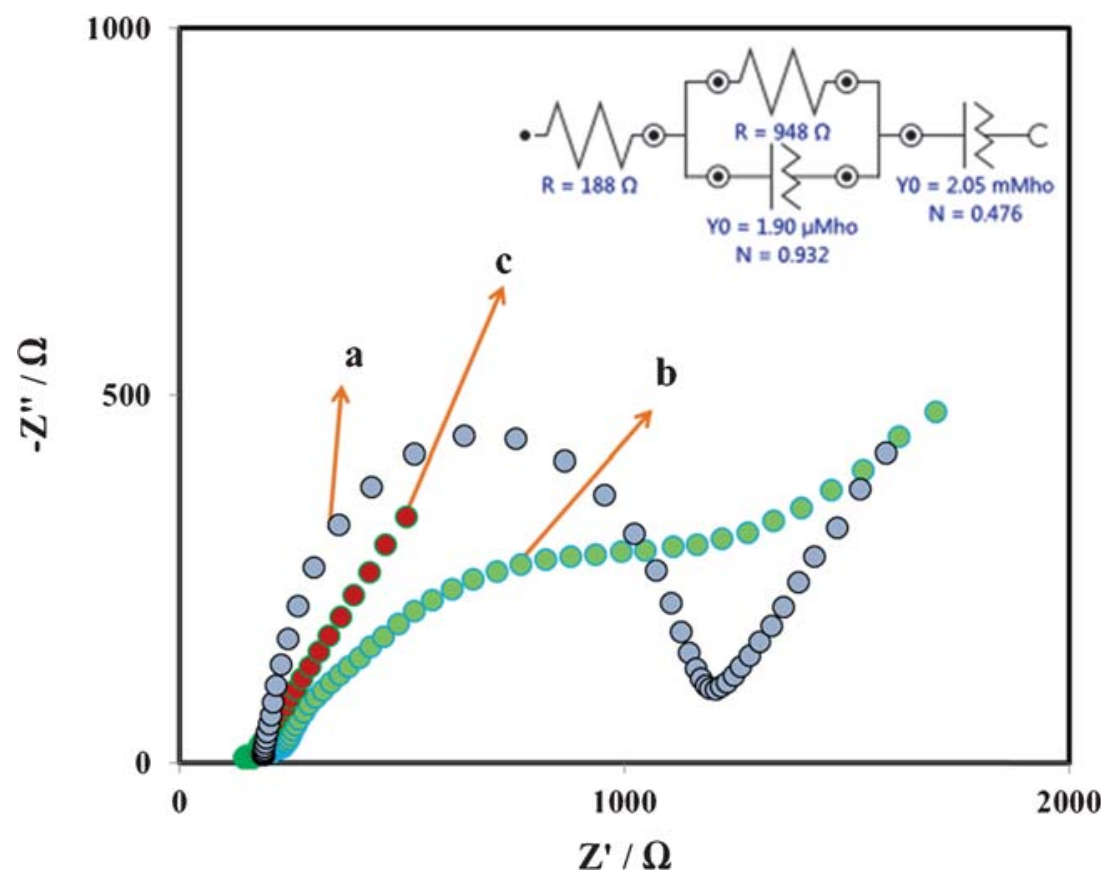

Figure 7. Nyquist plots of bare Au electrode (curve a), Au/PAF (curve b) and $\mathrm{Au} / \mathrm{AuNPs} / \mathrm{PEI} / \mathrm{CNT}-\mathrm{COOH} / \mathrm{PAF}$ (curve c) in $0.1 \mathrm{M} \mathrm{PBS}(\mathrm{pH}$ 2) containing 4 $\mathrm{mM} \mathrm{H} \mathrm{O}_{2}$ in the frequency range of $10 \mathrm{kHz}-0.1 \mathrm{~Hz}$.

modified electrode. For further investigation of the electrocatalytic properties of different modified electrodes, cyclic voltammograms of these electrodes in the presence of $\mathrm{H}_{2} \mathrm{O}_{2}$ at a wide potential range were recorded. The cyclic voltammetric responses of $\mathrm{Au}$ bare, Au/PAF and Au/AuNPs/PEI/CNT-COOH/PAF electrodes in the absence and presence of $4 \mathrm{mM} \mathrm{H}_{2} \mathrm{O}_{2}$ were recorded. $\mathrm{H}_{2} \mathrm{O}_{2}$ did not undergo reduction at $\mathrm{Au}$ electrode and weak catalytic effect was observed when $\mathrm{Au} / \mathrm{PAF}$ was used. However, presence of PAF film on $\mathrm{Au} / \mathrm{AuNPs} / \mathrm{PEI} / \mathrm{CNT}-\mathrm{COOH}$ electrode had excellent catalytic effect for reduction of $\mathrm{H}_{2} \mathrm{O}_{2}$. The result showed that in the absence of $\mathrm{H}_{2} \mathrm{O}_{2}$ a pair of redox peaks corresponding to the PAFox/PAF $\mathrm{R}_{\mathrm{R}}$ were observed at the surface of the tested electrodes. Upon addition of $\mathrm{H}_{2} \mathrm{O}_{2}$, an enhancement in the cathodic peak current was observed and the anodic peak current tended to decrease. The reason for this increase is that, along with the anodic potential sweep, $\mathrm{H}_{2} \mathrm{O}_{2}$ oxidises $\mathrm{PAF}_{\mathrm{R}}$ to $\mathrm{PAF}_{\mathrm{ox}}$, with simultaneous reduction of the regenerated $\mathrm{PAF}_{\text {ox }}$ which causes an increase in the cathodic current. For the same reason, the anodic current is smaller in the presence of $\mathrm{H}_{2} \mathrm{O}_{2}$, indicating that $\mathrm{PAF}_{\mathrm{R}}$ is consumed during a chemical step. Moreover, the electrocatalytic reduction peak current of $\mathrm{H}_{2} \mathrm{O}_{2}$ at Au/AuNPs/PEI/CNT$\mathrm{COOH} / \mathrm{PAF}$ electrode was $-640 \mu \mathrm{A}$, which was 4.5 times larger than that at Au/PAFelectrode $(-142 \mu \mathrm{A})$, which is in agreement with EIS data for charge transfer kinetics on different modified electrodes. These results indicate that the presence of PAF in the modified electrode has excellent catalytic activity toward $\mathrm{H}_{2} \mathrm{O}_{2}$ oxidation.

Cyclic voltammograms of different concentrations of $\mathrm{H}_{2} \mathrm{O}_{2}$ (ranging from 0.5 to $120 \mathrm{mM}$ ) at the modified electrode in $0.1 \mathrm{M}$ PBS ( $\mathrm{pH} 2)$ was recorded. The calibration curve based on the cathodic peak current is linear with the $\mathrm{H}_{2} \mathrm{O}_{2}$ concentration in the range of $0.5-120 \mathrm{mM}$ and a correlation coefficient of 0.996 (figure 8). The response of modified electrode was deviated from the linearity for $\mathrm{H}_{2} \mathrm{O}_{2}$ concentration above $120 \mathrm{mM}$. This behavior may be attributed to saturation of some redox sites on the surface of electrode, which are involved in the catalytic reaction. As can be seen from figure 8 by increasing the concentration of $\mathrm{H}_{2} \mathrm{O}_{2}$, the cathodic peak current of the modified electrode is increased while its anodic peak current decreased, indicating a typical electrocatalytic reduction process $\left(\mathrm{EC}^{\prime}\right)$. Therefore, an enhancement of peak current for the reduction of $\mathrm{H}_{2} \mathrm{O}_{2}$ indicates strong catalytic activity of $\mathrm{Au} / \mathrm{AuNPs} / \mathrm{PEI} / \mathrm{CNT}-\mathrm{COOH} / \mathrm{PAF}$ electrode.

In order to optimize the electrocatalytic response of the modified electrode, the effect of $\mathrm{pH}$ on the catalytic behavior of modified electrode was investigated. The cyclic voltammograms of the modified electrode in the presence of $2 \mathrm{mM}$ of $\mathrm{H}_{2} \mathrm{O}_{2}$ in $0.1 \mathrm{M}$ buffer solution at different $\mathrm{pH}$ values were recorded. At $\mathrm{pH}$ range of $1-3$, the modified electrode showed electrocatalytic activity, but catalytic currents decreased with 


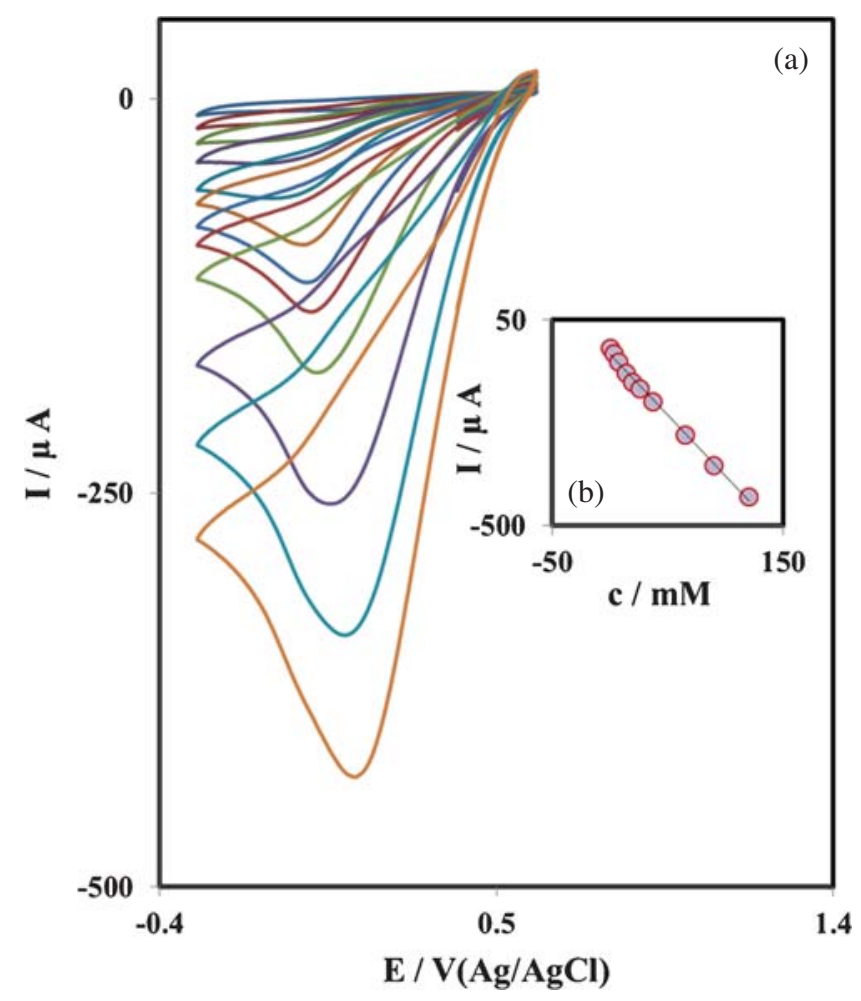

Figure 8. (a) $\mathrm{CVs}$ of the $\mathrm{Au} / \mathrm{AuNPs} / \mathrm{PEI} / \mathrm{CNT}-\mathrm{COOH} /$ PAF in the presence of different $\mathrm{H}_{2} \mathrm{O}_{2}$ concentration: $0.5,3$, $7,14,19,26,37,65,90$ and $120 \mathrm{mM}$, respectively in 0.1 M PBS (pH 2) at a scan rate of $50 \mathrm{mV} \mathrm{s}^{-1}$. (b) The plot of catalytic peak vs. $\mathrm{H}_{2} \mathrm{O}_{2}$ concentration.

increasing $\mathrm{pH}$ and at $\mathrm{pH} 4$ the catalytic effects of the modified electrode were negligible. The higher peak currents were observed at $\mathrm{pH} 2$ and this value was chosen as optimized. Owing to much higher reduction current obtained in solutions with lower $\mathrm{pH}$ values, we selected 2 as the suitable $\mathrm{pH}$ value for the detection of $\mathrm{H}_{2} \mathrm{O}_{2}$.

For investigation the electrocatalytic mechanism of the modified electrode toward $\mathrm{H}_{2} \mathrm{O}_{2}$ reduction, cyclic voltammograms of modified electrode in $4 \mathrm{mM} \mathrm{H}_{2} \mathrm{O}_{2}$ at different scan rates were recorded. Figure 9a illustrates cyclic voltammograms of $4 \mathrm{mM} \mathrm{H}_{2} \mathrm{O}_{2}$ using modified electrode that were recorded at potential sweep rates ranging from 10 to $200 \mathrm{mV} \mathrm{s}^{-1}$.

The magnification in the low scan rate $\left(10 \mathrm{mVs}^{-1}\right)$ was put in the figure 9a. As can be seen, for a low scan rate a catalytic effect for reduction of $\mathrm{H}_{2} \mathrm{O}_{2}$ was observed and a pair of redox peaks corresponding to $\mathrm{PAF}_{\mathrm{ox}} / \mathrm{PAF}_{\mathrm{R}}$ completely disappeared. While by increasing the scan rate, redox peaks corresponding $\mathrm{PAF}_{\mathrm{ox}} / \mathrm{PAF}_{\mathrm{R}}$ appeared confirming a typical electrocatalytic reduction process $\left(\mathrm{EC}^{\prime}\right)$. The peak current for the cathodic reduction of $\mathrm{H}_{2} \mathrm{O}_{2}$ is proportional to the square root of the scan rate, suggesting that the process is controlled by diffusion of analyte as expected for a catalytic system (figure 9b). It can also be noted that by increasing the sweep rate the peak potential for the catalytic reduction of $\mathrm{H}_{2} \mathrm{O}_{2}$ shifts to more negative values and the plot of peak current vs. square rate of scan rate deviates from linearity (at $v>100 \mathrm{mVs}^{-1}$ ), suggesting a kinetic limitation in the reaction between the redox sites of the PAF and $\mathrm{H}_{2} \mathrm{O}_{2}$. Based on the observed results, the following catalytic mechanism describes the reaction sequence in the reduction of $\mathrm{H}_{2} \mathrm{O}_{2}$.

$$
\begin{gathered}
\mathrm{PAF}_{(\mathrm{OX})}+2 \mathrm{e}^{-}+2 \mathrm{H}^{+} \longrightarrow \mathrm{PAF}_{(\mathrm{R})} \\
\mathrm{PAF}_{(\mathrm{R})}+\mathrm{H}_{2} \mathrm{O}_{2}+2 \mathrm{H}^{+} \rightarrow \mathrm{PAF}_{(\mathrm{OX})}+2 \mathrm{H}_{2} \mathrm{O}
\end{gathered}
$$

\subsection{Amperometric detection of $\mathrm{H}_{2} \mathrm{O}_{2}$ at the modified electrode}

Since amperometry under stirred conditions has a much higher current sensitivity than cyclic voltammetry, it was used to estimate the lower limit of detection. As discussed above, the Au/AuNPs/PEI/CNT-COOH/PAF electrode has excellent and strong mediation properties and facilitates the low potential amperometric measurements of $\mathrm{H}_{2} \mathrm{O}_{2}$. Figure 10 displays the typical steady-state catalytic current time response of $\mathrm{Au} / \mathrm{AuNPs} / \mathrm{PEI} / \mathrm{CNT}-\mathrm{COOH} / \mathrm{PAF}$ electrode with successive injection of $\mathrm{H}_{2} \mathrm{O}_{2}$ at an applied potential 0.01 V. A well-defined response was observed under the successive addition of $10 \mathrm{nM}$ of $\mathrm{H}_{2} \mathrm{O}_{2}$, which suggested a stable and efficient catalytic property through the AuNPs/PEI/CNT-COOH/PAF composite film. The reduction currents at the modified electrode were proportional to the concentration of $\mathrm{H}_{2} \mathrm{O}_{2}$ in the range of $10 \mathrm{nM}-150 \mathrm{nM}$. The limit of detection (LOD) of this method was calculated by using $3 S_{b} / b$, where $S_{b}$ is the standard deviation of the blanks, and $b$ is the slope of the calibration graph (Inset in figure 10).

The detection limit, linear calibration range and applied potential for $\mathrm{H}_{2} \mathrm{O}_{2}$ detection are reported in table 1 . These analytical parameters for the proposed modified electrode are comparable or better than the results recently reported for $\mathrm{H}_{2} \mathrm{O}_{2}$ determination at the surface of fabricated modified electrodes. ${ }^{34-41}$

\subsection{Stability study}

The long term stability of the Au/AuNPs/PEI/CNT$\mathrm{COOH} / \mathrm{PAF}$ modified electrode and the reversibility of its electrochemical behavior were also investigated. It 


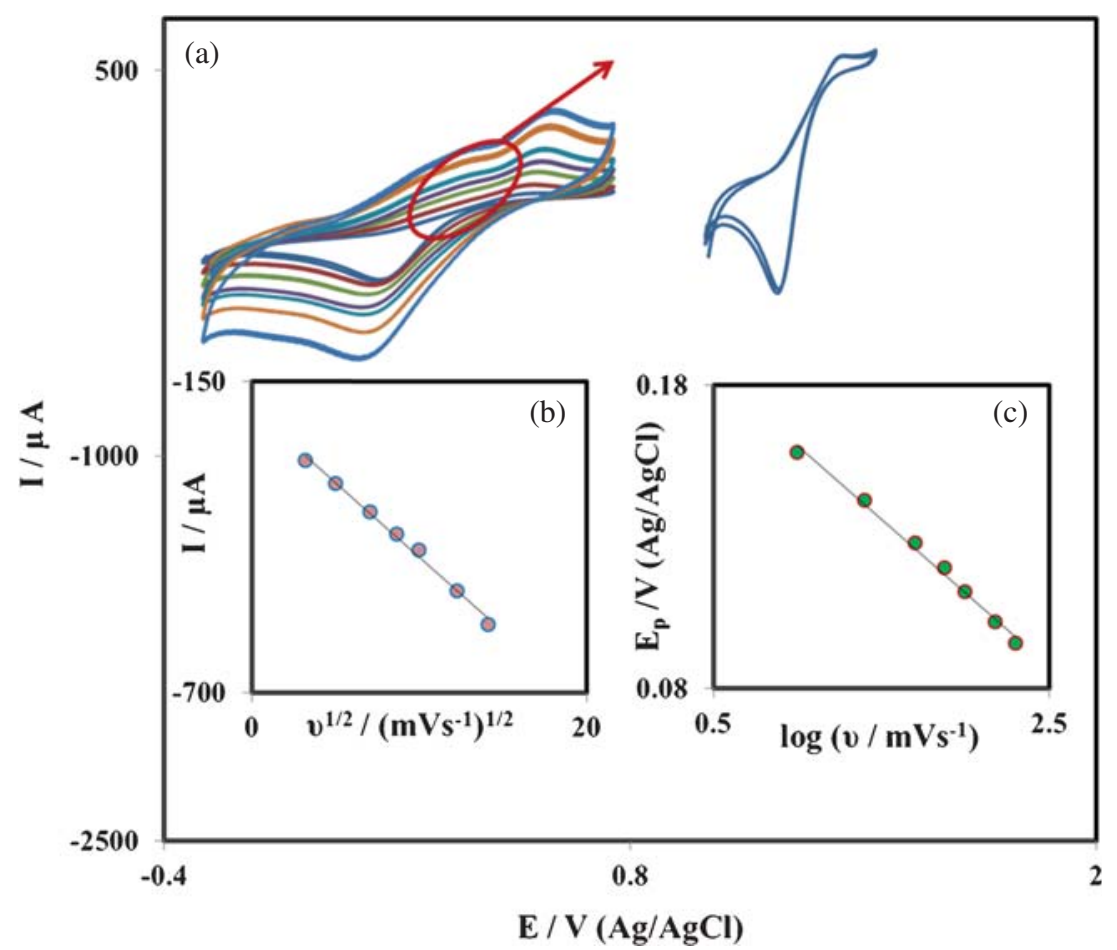

Figure 9. (a) Cyclic voltammograms of the modified electrode in the presence of $4 \mathrm{mM} \mathrm{H}_{2} \mathrm{O}_{2}$ at various scan rates: 10, 25, 50, 75, 100, 150 and 200 $\mathrm{mV} \mathrm{s}^{-1}$ in $0.1 \mathrm{M}$ PBS ( $\mathrm{pH}$ 2). (b) Variation of anodic peak currents vs. square root of potential scan rate. (c) dependence of the anodic peak potential versus $\log (v)$.

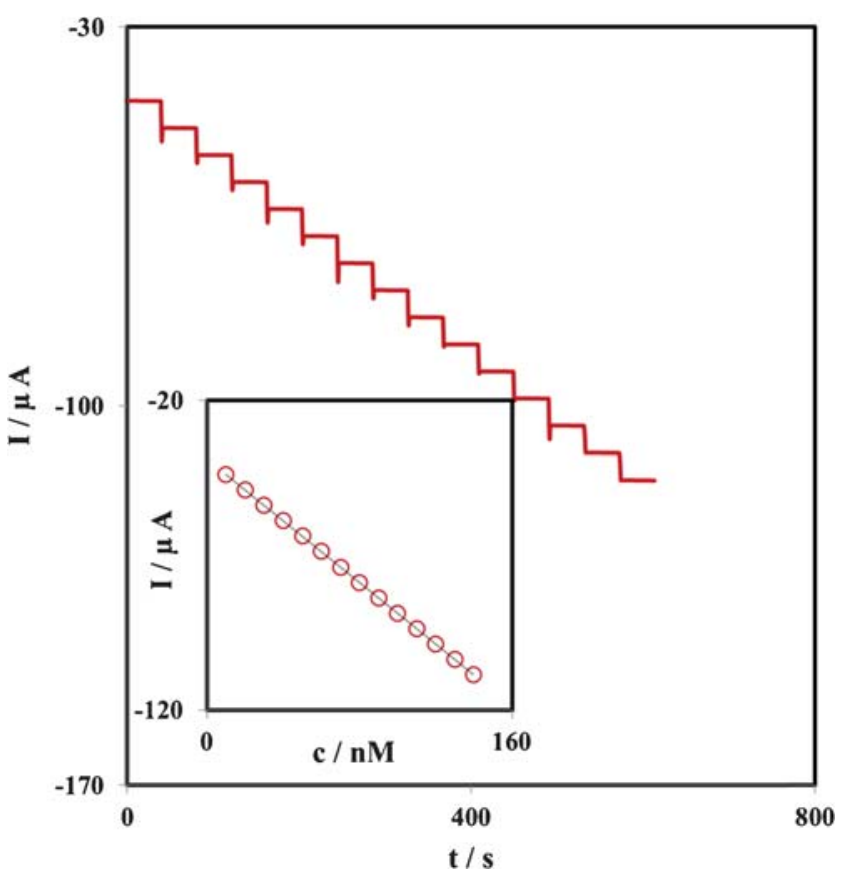

Figure 10. Amperometric response at Au/AuNPs/PEI/ $\mathrm{CNT}-\mathrm{COOH} / \mathrm{PAF}$ in $0.1 \mathrm{M} \mathrm{PBS}$ ( $\mathrm{pH}$ 2) held at $0.01 \mathrm{~V}$ for successive addition $10 \mathrm{nM} \mathrm{H} \mathrm{H}_{2}$. Inset: Plot of chronoamperometric currents vs. $\mathrm{H}_{2} \mathrm{O}_{2}$ concentration. was found that after storing the electrode in ambient condition for one week, the current and potential response of the recorded cyclic voltammograms remained almost unchanged. In addition, the operational stability of the modified electrode was examined by recording of the repetitive cyclic voltammograms in $0.1 \mathrm{M}$ acetate buffer solution. The results indicated that after 100 repetitive cycles at a scan rate of $50 \mathrm{mV} \mathrm{s}^{-1}$, no detectable change was observed in the peak height and potential separation. The high stability of Au/AuNPs/PEI/CNT-COOH/PAF modified electrode may be related to the mechanical and chemical stability of PAF film which leads to its stability against desorption and avoids its leaching into the solution.

In order to study the reproducibility of the electrode modification, five Au/AuNPs/PEI/CNT-COOH/PAF modified electrodes were prepared independently and their responses to $5 \mathrm{mM}$ of $\mathrm{H}_{2} \mathrm{O}_{2}$ were measured under identical conditions. The relative standard deviation (RSD) of measured cathodic peak currents was $6.4 \%$, which indicates that the fabrication method exhibits appreciable reproducibility. Similarly, the RSD for 5 successive $\mathrm{H}_{2} \mathrm{O}_{2}$ measurements $(5 \mathrm{mM})$ was $1.98 \%$ which indicates acceptable repeatability of the sensor. 
Table 1. Comparison of the performances of various hydrogen peroxide sensors.

\begin{tabular}{|c|c|c|c|}
\hline Matrix & LOD $\left(\mu \mathrm{mol} \mathrm{dm} \mathbf{d m}^{-3}\right)$ & Linear range $\left(\mu \mathrm{mol} \mathrm{dm} \mathbf{~}^{-3}\right)$ & Ref. \\
\hline $\mathrm{TH}^{1} / \mathrm{MWCNTs}^{2} / \mathrm{GC}^{3}$ & 0.83 & $10-6000$ & 34 \\
\hline chitosan/AgNWs ${ }^{4}$ & 2.00 & $8.00-1350$ & 35 \\
\hline $\mathrm{PTH}^{5} / \mathrm{Nafion} / \mathrm{HRP}^{6} / \mathrm{GC}$ & 60 & Up to 1000 & 36 \\
\hline $\mathrm{Co}_{3} \mathrm{O}_{4} / \mathrm{GCE}$ & 0.81 & $1.00-200$ & 37 \\
\hline $\mathrm{CuO} / \mathrm{GCE}$ & 0.12 & $10.0-200$ & 38 \\
\hline $\mathrm{MB}^{7}-\mathrm{HRP} / \mathrm{NME}^{8}$ & 1.00 & 4-2000 & 39 \\
\hline $\mathrm{NiO} / \mathrm{BmimBr}^{9} / \mathrm{Hb}-\mathrm{CPE}^{10}$ & 68.0 & $2.00-1050$ & 40 \\
\hline Nafion/Hb-GR-MWCNT/CILE ${ }^{11}$ & 0.0349 & $0.10-516$ & 41 \\
\hline This Work & 0.0056 & $0.01-0.15$ & - \\
\hline
\end{tabular}

${ }^{1}$ Thionine; ${ }^{2}$ Multi Wall Carbon Nanotube; ${ }^{3}$ Glassy Carbon; ${ }^{4}$ silver nanowires; ${ }^{5}$ Poly(thionine); ${ }^{6}$ Hourseradish peroxidase; ${ }^{7}$ Methylen blue; ${ }^{8}$ Nanotube modified Electrode; ${ }^{9} 1$-Butyl3-methylimidazolium bromide; ${ }^{10}$ Carbon Pate Electrode; ${ }^{11}$ Carbon Ionic Liquid Electrode.

\section{Conclusions}

We have demonstrated the suitability of Au/AuNPs/ $\mathrm{PEI} / \mathrm{CNT}-\mathrm{COOH} / \mathrm{PAF}$ as an ideal electrode catalyst for low-potential determination of $\mathrm{H}_{2} \mathrm{O}_{2}$ with a high sensitivity. The experimental results reported herein demonstrate that (i) the PAF can be firmly deposited on the $\mathrm{Au} / \mathrm{AuNPs} / \mathrm{PEI} / \mathrm{CNT}-\mathrm{COOH}$ by the consecutive potential cycling of the working electrode between $-0.05 \mathrm{~V}$ and $+0.8 \mathrm{~V}$ (vs. $\mathrm{Ag} / \mathrm{AgCl}$ ) in an acetate buffer solution (pH 4) containing $1.5 \times 10^{-3} \mathrm{M}$ acriflavine; (ii) the $\mathrm{Au} / \mathrm{AuNPs} / \mathrm{PEI} / \mathrm{CNT}-\mathrm{COOH} / \mathrm{PAF}$ can catalyze the reduction of $\mathrm{H}_{2} \mathrm{O}_{2}$ at $\mathrm{pH}$ 2; (iii) the kinetics of catalytic reaction is fast; and (iv) it is stable and has short response time, low detection limit, high sensitivity and low operation potential. It can be used as an amperometric electrochemical sensor for monitoring of $\mathrm{H}_{2} \mathrm{O}_{2}$.

\section{Acknowledgements}

The authors gratefully acknowledge the support of this work by the Khorramabad Branch, Islamic Azad University for financial support.

\section{References}

1. Li Y, Kuwabara H, Gong Y K, Takaki Y and Nakashima K 2003 J. Photochem. Photobiol., B 70171

2. Shamsipur M, Chaichi M J and Karami A R 2003 Spectrochim. Acta A 59511

3. Calatayud J M, Mateo J V G and David V 1998 Analyst 123429

4. Zi Y Q, Chen L G and Chen J 1999 Chin. J. Anal. Chem. 27691

5. Chen S M, Liu M I and Kumar S A 2007 Electroanalysis 19999
6. Lin K C and Chen S M 2006 J. Electrochem. Soc. 153 D91

7. Arora K, Prabhakar N, Chand S and Malhotra B D 2007 Biosens. Bioelectron. 23613

8. Lin T H and Ho K C 2006 Sol. Energy Mater. Sol. C 90 506

9. Li Y, Kuwabara H, Gong Y K, Takaki Y and Nakashima K 2003 J. Photochem. Photobiol., B 70171

10. Sharma V K, Sahare P D, Rastogi R C, Ghoshal S K and Mohan D 2003 Spectrochim. Acta Part A 591799

11. Yao S, Xu J, Wang Y, Chen X, Xu Y and Hu S 2006 Anal. Chim. Acta $\mathbf{5 5} 778$

12. Tarvin M, Cord B M, Mount K, Sherlach K and Millerd M L 2010 J. Chromatogr. A 12177564

13. Herberth D, Baum O, Pirali O, Roy P, Thorwirth S, Yamada K M T, Schlemmer S and Giesen T F 2012 J. Quant. Spectrosc. Ra. 1131127

14. Chen H, Zhang Z, Cai D, Zhang S, Zhang B, Tang J and Wua Z 2011 Talanta 86266

15. Xiang C, Zou Y, Sun L X and Xu F 2009 Sens. Actuators, $B \mathbf{1 3 6} 158$

16. Bo X J, Bai J, Wang L X and Guo L P 2010 Talanta 81 339

17. Liu Y, Wang D, Xu L, Hou H and You T 2011 Biosens. Bioelectron. 264585

18. Luque G L, Ferreyr N F, Leyva A G and Rivas G A 2009 Sens. Actuators, A 142331

19. Ammam M and Easton E B 2012 Sens. Actuators, B 161 520

20. Bienert G P, Schjoerring J K and Jahn T P 2006 Biochim. Biophys. Acta, Biomembr. 1758994

21. Dumitrescu I, Edgeworth J P, Unwin P R and Macpherson J V 2009 Adv. Mater. 213105

22. Harris P J F 2004 Int. Mater. Rev. 4931

23. Shu K, Qin Y, Luo H, Zhang P and Guo Z 2011 Mater. Lett. 651510

24. Deng C, Chen J, Yang M, Nie Z and Si S 2011 Electrochim. Acta 568851

25. Hu X, Wang T, Qu X and Dong S 2006 J. Phys. Chem. B 110853

26. Correa-Duarte M A, Sobal N, Liz-Marzan L M and Giersig M 2004 Adv. Mater. 162179 
27. Munoz E, Suh D S, Collins S, Selvidge M, Dalton A B, Kim B G, Razal J M, Ussery G, Rinzler A G, Martınez M T and Baughman R H 2005 Adv. Mater. 171064

28. Feng X, Mao C, Yang G, Hou W and Zhu J 2006 Langmuir 224384

29. Sun J J, Zhao H Z, Yang Q Z, Song J and Xue A 2010 Electrochim. Acta $\mathbf{5 5} 3041$

30. Shen M, Wang S H, Shi X, Chen X, Huang Q, Petersen E J, Pinto R A, Baker Jr. J R and Weber Jr. W J 2009 J. Phys. Chem. C 1133150

31. Swayambunathan V, Hayes D, Schmidt K H, Liao Y X and Meisel D 1990 J. Am. Chem. Soc. 1123831

32. Laviron E 1979 J. Electroanal. Chem. 10119

33. Bard A J and Faulkner L R 2000 In Electrochemical Methods: Fundamentals and Applications, 2nd ed. (New York: John Wiley)
34. Salimi A, Noorbaksh A, Mamkhezri H and Ghavami R 2007 Electroanalysis 191100

35. Salimi A, Korani A, Hallaj R, Khoshnavazi R and Hadadzadeh H 2009 Anal. Chim. Acta 63563

36. Yang X, Chen X, Zhang X, Yang W and Evans G G 2008 Sens. Actuators, B 129784

37. Gao X, Jin L, Wu Q, Chen Z and Lin X 2012 Electroanalysis 241771

38. Hou C, Xu Q, Yin L and Hu X 2012 Analyst 137 5803

39. Wang F, Kalam A, Chang L, Xie D, Al-Shihri A S and Du G 2013 Mater. Lett. 9296

40. Dong S, Zhang P, Liu H, Li N and Huang T 2011 Biosens. Bioelectron. 264082

41. Sun W, Cao L, Deng Y, Gong Sh, Shi F F, Li G G and Sun Z Z 2013 Anal. Chim. Acta 78141 